\title{
Electrophysiological variability in the SH-SY5Y cellular line
}

\author{
Silvia Santillo ${ }^{1}$, Aniello Schiano Moriello ${ }^{2}$ and Vito Di Maio ${ }^{1}$ \\ ${ }^{1}$ Institute of Cybernetics "E. Caianiello" of the CNR, c/o Comprensorio “Olivetti”, Via Campi Flegrei 34, 80078, Pozzuoli \\ (NA), Italy \\ ${ }^{2}$ Institute of Biomolecular Chemistry of the CNR, c/o Comprensorio "Olivetti", Via Campi Flegrei 34, 80078, Pozzuoli (NA), \\ Italy
}

\begin{abstract}
The basic electrophysiological properties of SH-SY5Y tumour cells have been studied by whole cell patch-clamp in voltage clamp configuration. The results shown the existence of a large variability of the response among individual cells in the same experimental conditions. Experiments conducted by using different ionic concentrations of the recording pipette filling solution, yielded a significant variability of peak current amplitude for all the filling solutions used. In addition, variability among groups was detected. The inter-group variability was not dependent on the different ionic components among the groups. Our results confirm earlier findings that this cell line is not constituted of an uniform population of cells. Moreover, from the present results we can conclude that these cells have diverse regulatory patterns of membrane conductance, probably due to both the expression as well as a non precise regulation of the membrane density of the different channels.
\end{abstract}

Key words: Whole-cell patch-clamp - SH-SY5Y — Ion channels

\section{Introduction}

SH-SY5Y is a cellular sub-line cloned from original SK-N$\mathrm{SH}$ line obtained from neuroblastoma tumour cells. These cells are usually classified as neuroblastic-type (N-type) and they show neuronal-like morphology, some neuronal markers and the ability to evoke spikes when stimulated by depolarizing steps. They are relatively easy to grow in culture and to manipulate for several experimental purposes. Moreover, they can be induced to differentiate in to specific neuronal types with different agents or under different growth conditions (Encinas et al. 2000). Undifferentiated cells express dopamine (DOPA) producing enzymes, DOPA receptors and DOPA transporters rendering them a good model for the study of the Parkinson's disease (for a review, see Xie et al. 2010). They also have a high level of noradrenaline content and of choline acetyl transferase (ChAT) activity denoting a noradrenergic/cholinergic phenotype. Treatment with retinoic acid (RA) enhances the cholinergic phenotype (Dunckley and Lukas 2006; Xie et al. 2010).

Correspondence to: Silvia Santillo, Istituto di Cibernetica "E. Caianiello" del CNR, Via Campi Flegrei 34, 80078, Pozzuoli (NA), Italy E-mail: s.santillo@cib.na.cnr.it
SH-SY5Y cells have been also used in studies of Alzheimer's disease since they lack the mature iso-form of tau (a protein involved in Alzheimer's degeneration). Treatment with RA, followed by brain-derived neurotrophic factor (BDNF), turns these cells into a neuron-like cell model, more suitable for studying the mechanisms of tau phosphorylation (Jämsä et al. 2004; Agholme et al. 2010).

Concerning the electrophysiological properties of these cell lines, both undifferentiated and differentiated cells have voltage-gated channels in the plasma membrane (Forsythe et al. 1992a, 1992b). However, the differentiation process produces variations in the membrane conductance (Toselli et al. 1996; Tosetti el al. 1998). Differentiated cells seem to acquire the neuronal ability to produce bursts of spikes unlike those undifferentiated ones that usually show single spikes only (Tosetti et al. 1998). Like neurons, spike activity is due to fast variations in conductance of $\mathrm{Na}^{+}$and $\mathrm{K}^{+}$ions, producing inward and outward currents respectively. Inward currents are predominantly tetrodotoxin (TTX) sensitive and hence carried by $\mathrm{Na}^{+}$(Toselli et al. 1996). Outward currents, being inactivated by tetraethylammonium (TEA), cesium (Cs) and 4 -aminopyridine, are largely produced by $\mathrm{K}^{+}$(Tosetti et al. 1998; Friederich et al. 2002).

Although the RA-dependent differentiation is considered a good way to have a stable neuron model, it has been found 
to be effective only for periods shorter than 5 days, after which reversion to the undifferentiated state can occur in a high percentage of cells (Encinas et al. 2000). RA-induced differentiation, associated with total removal of calf serum from cell cultures and addition of BDNF, produces a stable population (up to 3 weeks) of neuron-like cells with a profuse neuritic net (Encinas et al. 2000).

Despite their wide use in several different areas of neurophysiology, the suitability of the undifferentiated cells for electrophysiological experiments has never been established.

In preliminary whole cell recordings, on native $\mathrm{SH}-\mathrm{SY} 5 \mathrm{Y}$ cells, we observed a great variability of responses to depolarizing stimuli. For specific stimuli, some cells responded with $\sim 0 \mathrm{pA}$ inward current while others displayed a peak up to $300 \mathrm{pA}$. This variability was more evident for holding level of $-40 \mathrm{mV}$ but was present also for holding level of $-90 \mathrm{mV}$. Since these cells are often used in electrophysiological experiments related to membrane excitability, both in physiological and pathological conditions, we planned a systematic study of the basic electrophysiological properties of undifferentiated SH-SY5Y which is the topic of the present work. We used three different pipette filling solutions (A, B and C - compositions see in Materials and Methods) and for each of them we evaluated statistically the variability of the responses by using a simple protocol of depolarizing steps. We also compared the differences among the above groups both in the amplitude and in variability of the evoked response.

\section{Materials and Methods}

Human neuroblastoma cells SH-SY5Y were cultured in Dulbecco's Modified Eagle Medium (DMEM) supplemented with $20 \%$ of fetal bovine serum and with $100 \mathrm{IU} / \mathrm{ml}$ penicillin and $100 \mu \mathrm{g} / \mathrm{ml}$ of streptomycin. Incubation was carried in $5 \% \mathrm{CO}_{2}$ at $37^{\circ} \mathrm{C}$. Cells were grown on circular slides of $8 \mathrm{~mm}$ diameter coated with poly-L-lysine $(0.01 \%$ water solution) and were used for experiments until they were 50-70\% confluent (1000-8000 per slides). They were used at 16 th passage and recordings were done between the $3 \mathrm{rd}$ and 12th day of the culture on the slide.

For whole-cell recordings, a slide was removed and washed with extracellular medium composed of (in $\mathrm{mM}$ ): $130 \mathrm{NaCl} ; 4 \mathrm{KCl} ; 2 \mathrm{CaCl}_{2} ; 1 \mathrm{MgCl}_{2} ; 10$ HEPES; 10 glucose ( $\mathrm{pH}$ adjusted to 7.4 with $\mathrm{NaOH}$ ). The slide was held in the recording chamber filled with the same solution.

Recording electrodes were prepared from borosilicate glass capillary ( $1.5 \mathrm{~mm}$ of outer diameter, $0.86 \mathrm{~mm}$ of inner diameter, furnished by Clark Electrical Instruments), pulled and fire polished by P1000 horizontal Sutter puller. Tip diameter of electrodes ranged between 2-2.5 $\mu \mathrm{m}$ and resistance $\left(R_{e}\right) 3-7 M \Omega$. They were filled alternatively with three commonly used solutions having the following compositions in $\mathrm{mM}$ ( $\mathrm{pH}$ adjusted to $\mathrm{pH} 7.3$ with $\mathrm{KOH}$ ): solution A: $140 \mathrm{KCl}, 4 \mathrm{NaCl}, 2 \mathrm{MgCl}_{2}, 0.02 \mathrm{CaCl}_{2}, 0.8$ EGTA-KOH, 10 HEPES, $4 \mathrm{Mg}$-ATP; solution B: $130 \mathrm{~K}$-gluconate, $10 \mathrm{NaCl}$, $2 \mathrm{MgCl}_{2}, 1 \mathrm{CaCl}_{2}, 10$ EGTA-KOH, 10 HEPES, 2 Mg-ATP; solution C: $10 \mathrm{KCl}, 110 \mathrm{~K}$-gluconate, $10 \mathrm{NaCl}, 2 \mathrm{MgCl}_{2}, 1$ $\mathrm{CaCl}_{2}, 10$ EGTA-KOH, 10 HEPES, $2 \mathrm{Mg}$-ATP. An additional solution $\mathrm{D}$ with same composition of solution A but with $\mathrm{CsCl}$ instead of $\mathrm{KCl}$ was used to test the possible influence of ions different from $\mathrm{K}^{+}$in both response amplitude and its variability of outward currents. The concentration of the principal ions involved in current production as well as their equilibrium potential $\left(E_{\text {ion }}\right)$ computed by Nernst equation for a temperature of $25^{\circ} \mathrm{C}$ is reported in Table 1.

Patch clamp recordings were carried out at room temperature $\left(20-25^{\circ} \mathrm{C}\right)$.

The recording apparatus was composed of an EPC7 amplifier connected to a Digidata 1200 D/A board controlled by PClamp8 software. Both current and voltage signals were sampled at $20 \mathrm{kHz}$ and filtered at $3 \mathrm{kHz}$ by the built in EPC7 filter system. Additional offline statistical analysis was performed by Statview 5 .

Gigaseal resistance ranged 5-20 G $\Omega$. Once gigaseal formation was obtained, fast capacitance was compensated and then whole-cell configuration was obtained by a gentle suction. Recordings were performed only when series resistance $\left(\mathrm{R}_{\mathrm{S}}\right)$ was less than twice the electrode resistance $\left(\mathrm{R}_{\mathrm{s}}<2 \mathrm{R}_{\mathrm{e}}\right)$ and, in any case not greater than $10 \mathrm{M} \Omega$. Cell capacitance

Table 1. Ionic concentration of the medium and of the filling solutions A, B, C, D and corresponding Nernst's equilibrium potentials

\begin{tabular}{|c|c|c|c|c|c|c|c|c|c|}
\hline \multirow[t]{2}{*}{ Ion } & \multirow{2}{*}{$\frac{\text { Medium }}{\mathrm{c}}$} & \multicolumn{2}{|c|}{ Solution A } & \multicolumn{2}{|c|}{ Solution B } & \multicolumn{2}{|c|}{ Solution C } & \multicolumn{2}{|c|}{ Solution D } \\
\hline & & c & $\mathrm{E}_{\text {ion }}$ & c & $\mathrm{E}_{\text {ion }}$ & c & $\mathrm{E}_{\text {ion }}$ & c & $\mathrm{E}_{\mathrm{ion}}$ \\
\hline $\mathrm{Na}^{+}$ & 130 & 4 & 89.38 & 10 & 65.85 & 10 & 65.85 & 4 & 89.38 \\
\hline $\mathrm{K}^{+}$ & 4 & 140.8 & -91.43 & 140 & -91.28 & 130 & -89.38 & - & - \\
\hline $\mathrm{Cl}^{-}$ & 150 & 148.04 & -0.34 & 16 & -57.46 & 26 & -45.35 & 148.04 & -0.04 \\
\hline $\mathrm{Ca}^{2+}$ & 2 & 0.04 & 50.12 & 1 & 8.90 & 1 & 8.90 & 0.04 & 50.12 \\
\hline $\mathrm{Cs}^{+}$ & - & - & - & - & - & - & - & 140 & - \\
\hline
\end{tabular}

c, concentration of ions (in $\mathrm{mM}$ ); $\mathrm{E}_{\text {ion }}$, equilibrium potential of ions (in $\mathrm{mV}$ ). 
and $\mathrm{R}_{\mathrm{s}}$ were compensated (40-60\%). The $\mathrm{P} / 6$ sub-pulse correction of cell leakage and capacitance was used after verification that this correction did not affect the amplitude of the peak current.

The number of cells analysed were 14, 120, 12 and 14 for the groups A, B, C and D respectively.

The same stimulating protocol was applied for all groups by using two different holding potentials $\left(\mathrm{V}_{\mathrm{H}}\right),-40 \mathrm{mV}$ and $-90 \mathrm{mV}$, respectively. Only data from cells that completed the protocol both for holding level of $-40 \mathrm{mV}$ and $-90 \mathrm{mV}$, were included in the statistical analysis. When protocol was applied on the same cell for more than a single time, data were averaged and a single data point was considered for each cell at any stimulus level. The protocol consisted of a series of voltage steps of $50 \mathrm{~ms}$ duration, starting from -40 $\mathrm{mV}$ to $+90 \mathrm{mV}$ (10 mV of increment at each step (see Figure 1f). No correction for junction potentials was applied.

In voltage clamp configuration both the current peaks and the membrane capacitances were recorded.
The peaks, both positive and negative, were converted in current densities (Den) according to the formula

$$
\text { Den }=\frac{I_{\text {peak }}}{C_{m}}
$$

where $I_{\text {peak }}$ is the peak current (pA) and $C_{m}$ is the membrane capacitance $(\mathrm{pF})$. The current density renders the results independent on the cell size because membrane capacitance is a descriptor of the cell surface. The analysis of Den was performed by ANOVA, Fisher's test and Student $t$-test for each group and among groups. As descriptor of variability we used the standard deviation (SD). Linear regression was used to correlate the mean current density to the variability expressed in terms of SD.

Immediately after the patch rupture and before any further compensation, membrane voltage $\left(\mathrm{V}_{\mathrm{m}}\right)$ was recorded in current-clamp configuration at $0 \mathrm{pA}$ holding level which is considered as the most probable resting potential $\left(V_{R}\right)$ in natural conditions.

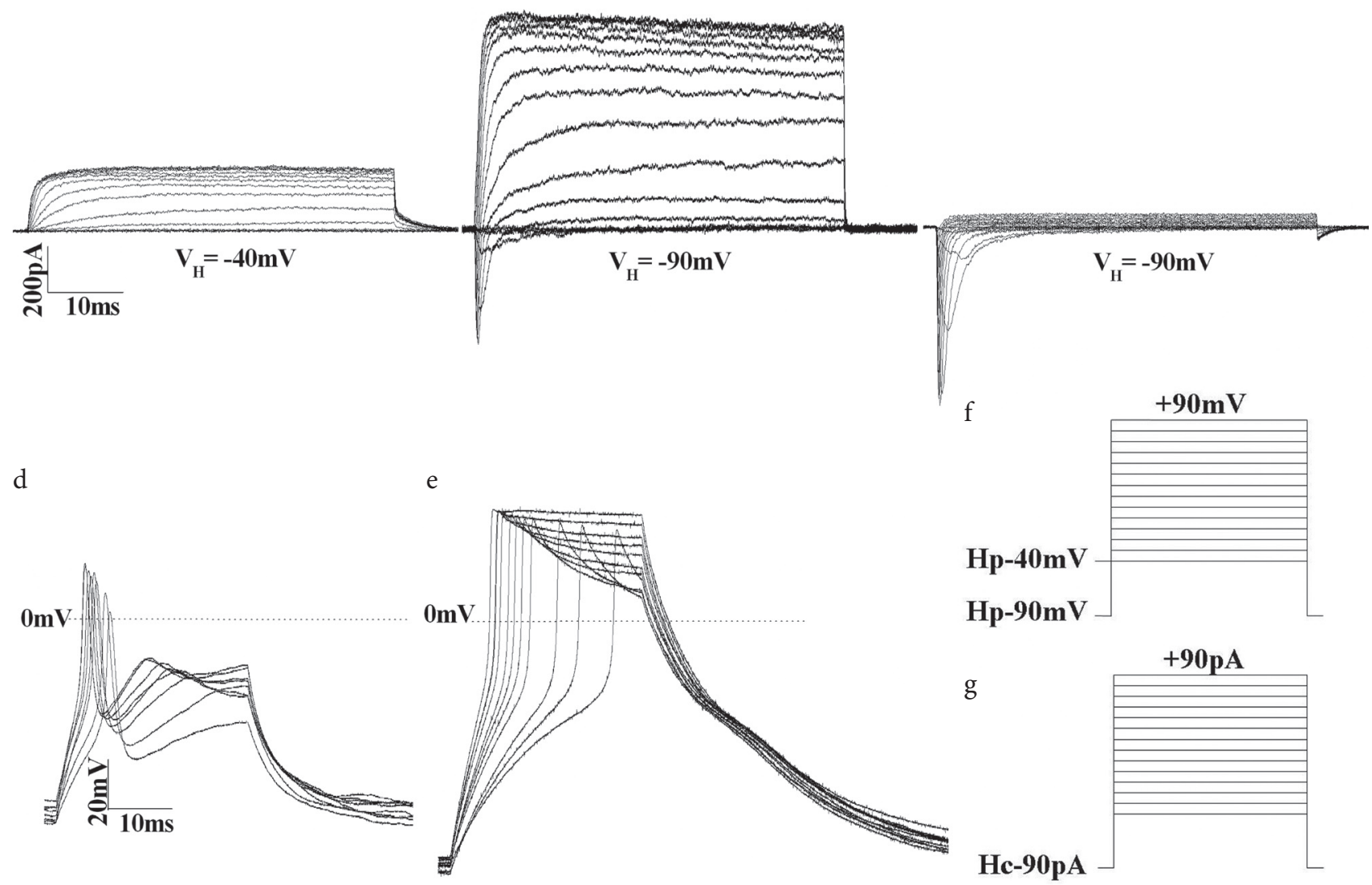

Figure 1. Example of current recording in voltage clamp configuration at holding potential $\left(\mathrm{V}_{\mathrm{H}}\right)-40 \mathrm{mV}$ for solution $\mathrm{A}$ (a), $-90 \mathrm{mV}$ for solution A (b) and $-90 \mathrm{mV}$ for solution $\mathrm{D}(\mathrm{c})$. Example of voltage recording in current-clamp configuration at holding current $-90 \mathrm{pA}$ for solution C (d) and for solution D (e). Protocol applied in voltage clamp configuration for two different $\mathrm{V}_{\mathrm{H}}-40 \mathrm{mV}$ and $-90 \mathrm{mV}$ (f). Protocol applied in current-clamp mode for holding current $-90 \mathrm{pA}(\mathrm{g})$. 
In some cases, to test the ability of these cells to emit spikes, we also carried out recordings in current-clamp configuration at three different levels of the holding current (0 $\mathrm{pA},-70 \mathrm{pA}$ and $-90 \mathrm{pA}$ ) corresponding to $\mathrm{V}_{\mathrm{R}}$ and to values of $\mathrm{V}_{\mathrm{m}}$ ranging from $-50 \mathrm{mV}$ to $-110 \mathrm{mV}$. A similar protocol as that of the voltage clamp configuration was applied using step currents of $10 \mathrm{pA}$, with stimulus duration of $50 \mathrm{~ms}$, till to the value of $+90 \mathrm{pA}$ (Figure $1 \mathrm{~g}$ ).

\section{Results}

Resting potentials $\left(\mathrm{V}_{\mathrm{R}}\right)$, registered immediately after the whole cell configuration was obtained, were $-47.71 \pm$ $8.36 \mathrm{mV}(n=14),-26.42 \pm 11.89 \mathrm{mV}(n=46)$ and $-31.84 \pm$ $22.61 \mathrm{mV}(n=20)$ for the solutions A, B and C, respectively. Differences among $\mathrm{V}_{\mathrm{R}}$ obtained in the three solutions were analysed by using paired t-test with a confidence interval of 95\%. Comparison of mean $\mathrm{V}_{\mathrm{R}}$ obtained with solutions $\mathrm{A}$ and $\mathrm{B}$ showed a marked difference $(\mathrm{t}=-4.48, p<0.001)$ as well as those obtained comparing solutions $\mathrm{A}$ and $\mathrm{C}(\mathrm{t}=-2.84$, $p<0.05)$ but no statistical difference was detected in the $V_{R}$ between the solutions B and C $(t=0.42, p>0.05)$.

Figure 1a,b show current traces obtained at holding levels of $-40 \mathrm{mV}$ and $-90 \mathrm{mV}$, respectively. The outward currents in Fig. 1c, where solution D was used, were reduced $~ 90 \%$ with respect to those registered with solutions $\mathrm{A}, \mathrm{B}$ and $\mathrm{C}$.
This shows that the major components of outward current are $\mathrm{K}^{+}$ions. Fig. $1 \mathrm{~d}$ shows an example of spikes recorded in current-clamp configuration. It has to be noted that always only single spike (and never bursts) were registered, independently of the stimulus duration (data not shown). The spikes shown in Fig. 1e were obtained with solution D and clearly they lacked the classical repolarising phase due to $\mathrm{K}^{+}$currents.

We never observed spike activity in current clamp configuration when holding level was set to $0 \mathrm{pA}$ (virtually when $\mathrm{V}_{\mathrm{m}}=\mathrm{V}_{\mathrm{R}}$ ). It would seem that these cells are able to produce spikes only when hyperpolarised and more precisely when their $\mathrm{V}_{\mathrm{m}}$ (see above) is forced towards the $\mathrm{V}_{\mathrm{R}}$ of normal neurons $\left(\mathrm{V}_{\mathrm{R}}<-60 \mathrm{mV}\right)$.

The mean Den \pm SD is plotted respectively for inward (Fig. 2) and for outward currents (Fig. 3) as function of the voltage level of the stimulus for the filling solutions $\mathrm{A}, \mathrm{B}$ and $\mathrm{C}$, both at the $\mathrm{V}_{\mathrm{H}}-40 \mathrm{mV}$ and $-90 \mathrm{mV}$.

Comparison of Fig. 3 and 4 immediately shows the quantitative effect of the replacement of $\mathrm{K}^{+}$with $\mathrm{Cs}^{+}$which reduced the outward current by $90 \%$ on average.

It is evident that some depolarizing steps produce currents not significantly different from zero. If we define as "significant current" those produced by depolarizing steps that show a significant peak response the current density computed from these peaks could be defined as significant Den.
A

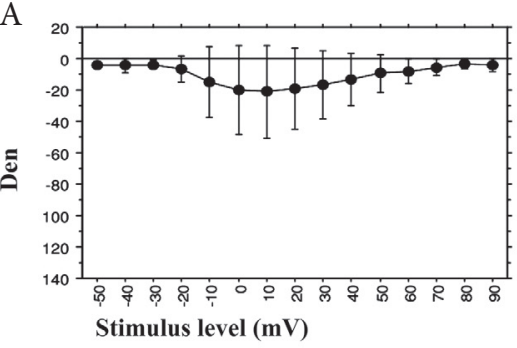

Inward current density $V_{H}=-40 m V$

B

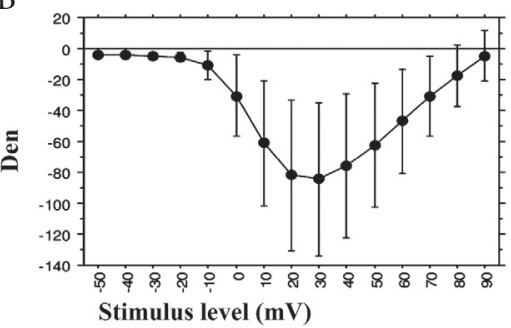

Inward current density $V_{H}=-90 m V$

A
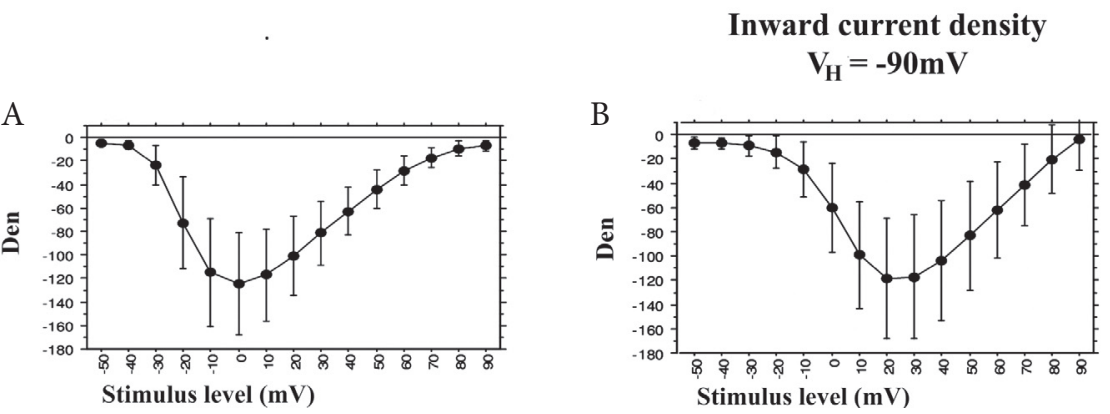

C

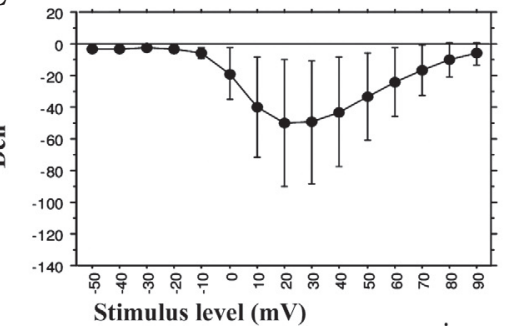

C

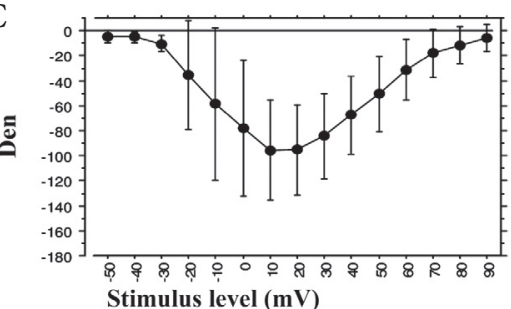

Figure 2. Inward current density ( mean Den $\pm \mathrm{SD}$ ) plotted for inward currents as function of the stimulus level for the filling solutions $\mathrm{A}, \mathrm{B}$ and $\mathrm{C}$ at $\mathrm{V}_{\mathrm{H}}=-40 \mathrm{mV}$ and $\mathrm{V}_{\mathrm{H}}=-90 \mathrm{mV}$. 

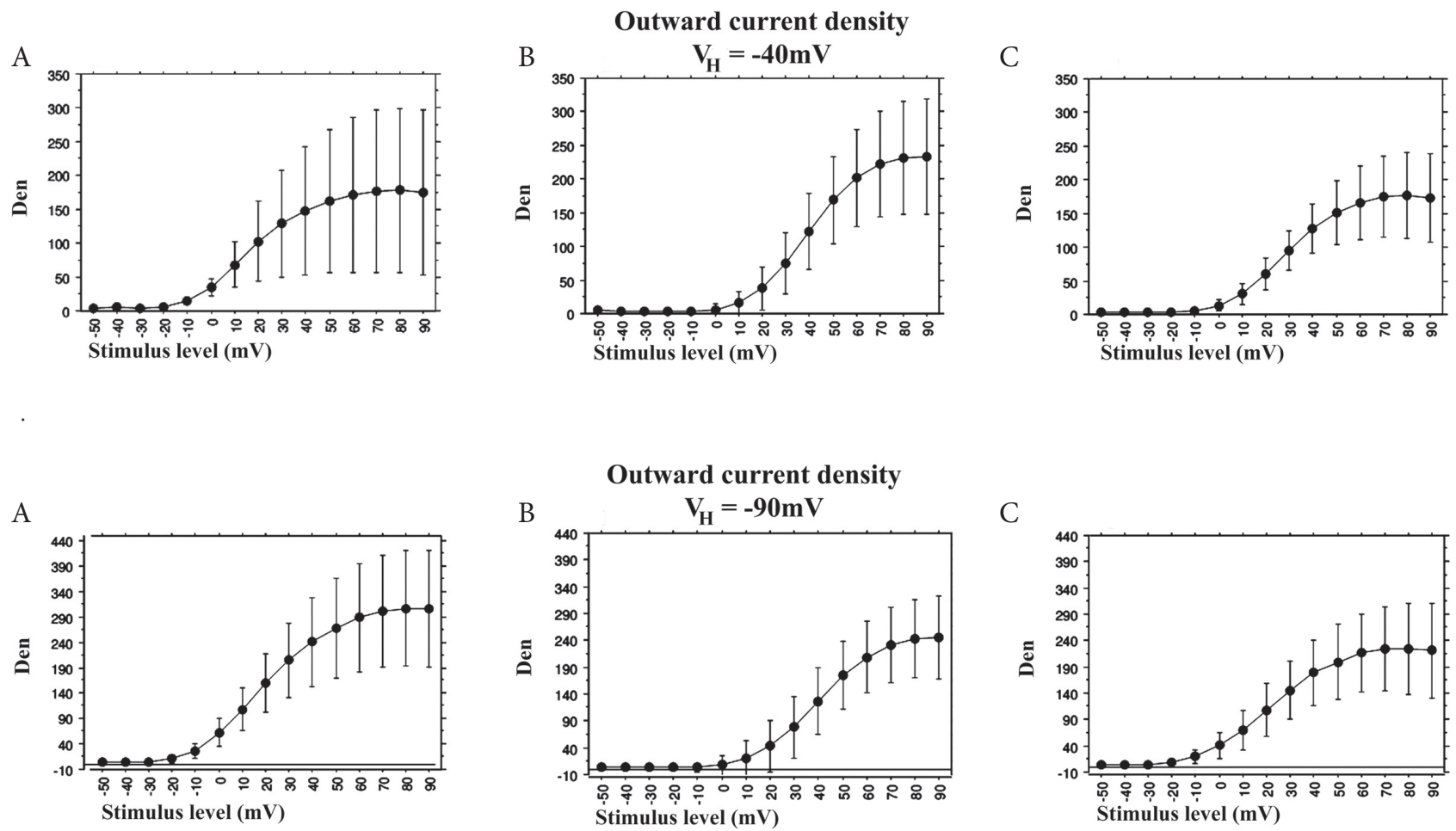

Figure 3. Outward current density ( mean Den \pm SD) plotted for outward currents as function of the stimulus level for the filling solutions $\mathrm{A}, \mathrm{B}$ and $\mathrm{C}$ at $\mathrm{V}_{\mathrm{H}}=-40 \mathrm{mV}$ and $\mathrm{V}_{\mathrm{H}}=-90 \mathrm{mV}$.

In Fig. 2 and 3 it seems evident that, for depolarizing steps producing significant Den, both inward and outward current densities present a large variability (large SD) for all the filling solutions used.

We have also noted that, for the holding level of $-40 \mathrm{mV}$, some cells, for some depolarizing steps, produced no inward currents while others gave peaks greater than 300 pA. Fig. 1a shows an example where no inward current was recorded for any depolarizing step (solution B). This response diversity was neither dependent on the solution used nor on the passage step or growing time of cell cultures since we observed these effects also among cells of the same culture slide, during the same experimental session (data not shown).

Apparently SD also increases as a function of mean Den. A dependence of SD on the size of current can be expected for low values of Den (small currents can have only small variability which can increase with current size). However, for large values of Den, variability should not be dependent on the Den amplitude, but should be more or less constant. To test the existence of this dependence, we plotted SD as a function of mean Den and we fitted data both with exponential and linear models (see Fig. 5 and 6).

\section{Outward current density}

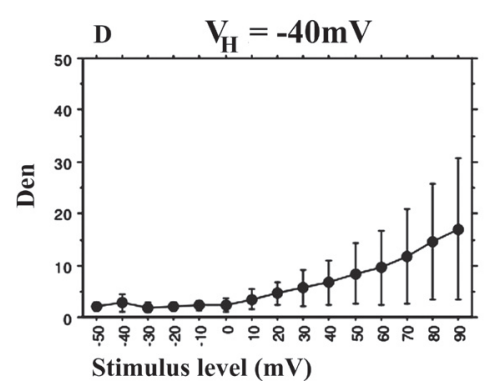

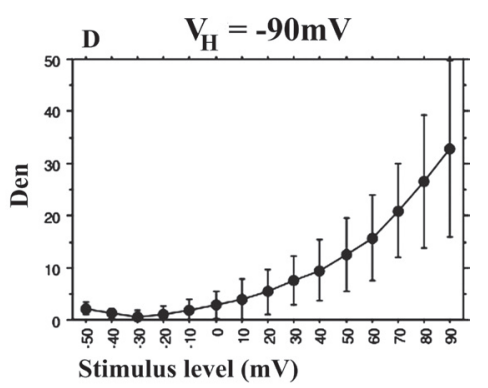

Figure 4. Outward current density ( mean Den \pm $\mathrm{SD})$ plotted for outward currents as function of the stimulus level for the filling solution $\mathrm{D}$, at $\mathrm{V}_{\mathrm{H}}=$ $-40 \mathrm{mV}$ and the $\mathrm{V}_{\mathrm{H}}=-90 \mathrm{mV}$. 
A

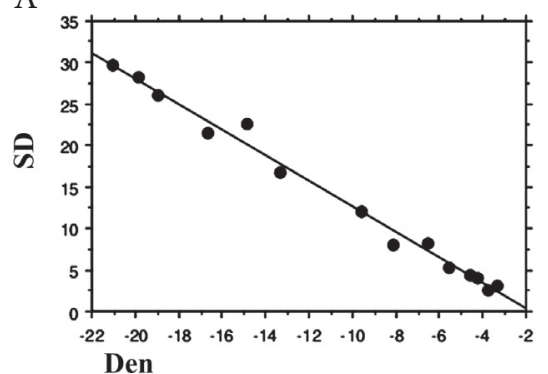

A

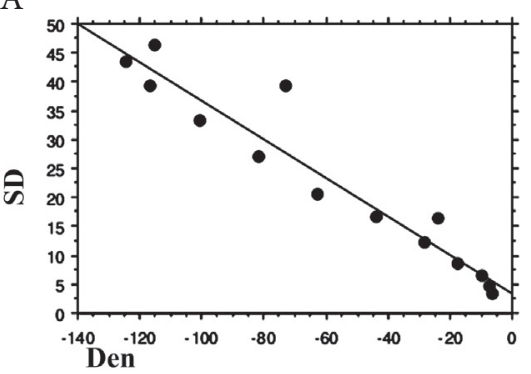

Inward current density

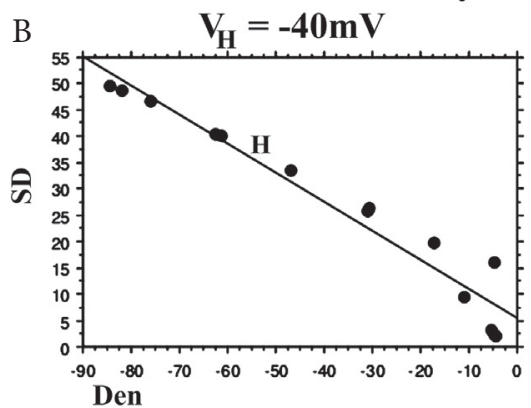

Inward current density

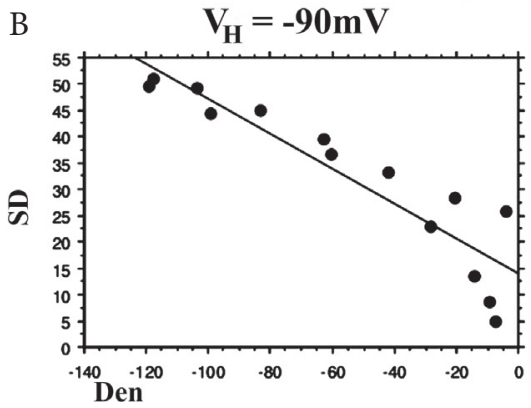

C

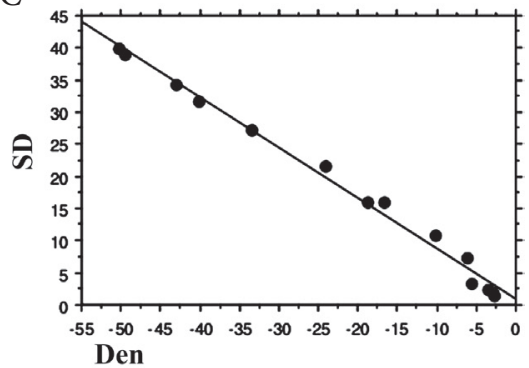

C

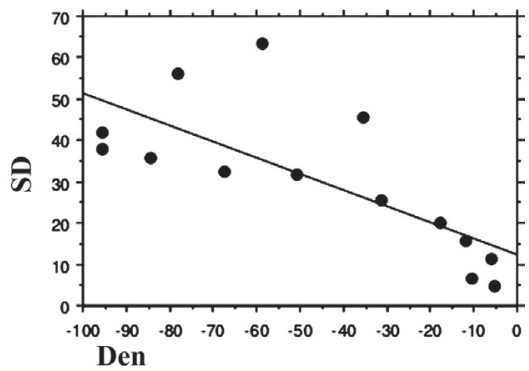

Figure 5. Linear model data fitting for the comparison of $S D v s$. Den for inward currents at $V_{H}=-40 \mathrm{mV}$ and the $V_{H}=-90 \mathrm{mV}$ for the solutions $\mathrm{A}, \mathrm{B}$ and $\mathrm{C}$.

Excluding the solution $C$, that showed a correlation coefficient $(R)$ smaller than 0.6 , all the other tests showed $R>$ 0.8 and in most of the cases, $R$ was greater than 0.9 . This clearly indicated that the sizes of Den and SD are positively correlated and this means that increasing the size of Den increases also SD. A second order exponential model in some cases increased the value of $R$ non significantly with respect to the linear model. In Fig. 5 and 6 the linear interpolation of data is shown for simplicity.

This dependence also occurs among the different solutions in the sense that, for a given step, the solution that showed the higher Den, also showed a higher SD (Fig. 5 and 6).

Finally, we tested differences of mean Den among solutions $\mathrm{A}, \mathrm{B}$ and $\mathrm{C}$ by ANOVA with a confidence interval of 95\% (Tables 2, 3, 4, 5).

From these tables it is evident that for the steps producing significant Den, at both $\mathrm{V}_{\mathrm{H}}$ of $-40 \mathrm{mV}$ and $-90 \mathrm{mV}$, differences of mean Den are always significant for outward and inward current densities when comparing A-B groups. Apparently, there is no significant difference in inward Den between solutions $\mathrm{A}$ and $\mathrm{C}$ and this can be then due to the very large intra-group variability of solution A. This effect is less evident at holding level of $-90 \mathrm{mV}$.
We computed, for each solution, the values of the expected Den according to Ohm's law assuming for simplicity the density as current

$$
\text { Den }=I_{\text {ion }}=g_{\text {ion }}\left(V_{m}-E_{\text {ion }}\right)
$$

where $g_{i o n}$ is the conductance for the peak current at a given voltage level, $V_{m}$ is the stimulus amplitude and $E_{i o n}$ is the Nernst equilibrium potential for a given ion.

Since inward current is due mainly to $\mathrm{Na}^{+}$(Toselli et al. 1996) and outward current is due to $\mathrm{K}^{+}$(Tosetti et al. 1998, and see Figure 4 in this text), the expected mean Den from inward current will be

$$
\operatorname{Den}_{i n w}=I_{N a+}=g_{N a+}\left(V_{m}-E_{N a+}\right)
$$

and for the outward current will be

$$
\operatorname{Den}_{\text {outw }}=I_{K+}=g_{K+}\left(V_{m}-E_{K+}\right)
$$

Once computed the expected Den for each solution, we also computed the observed difference of Den among the groups by Fisher's test for the hypothesis that these differences are zero $(\mathrm{H} 0=0)$. Tables $2,3,4$ and 5 show the ANOVA 
A

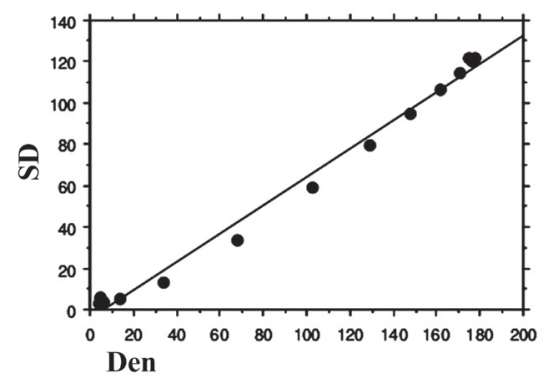

A

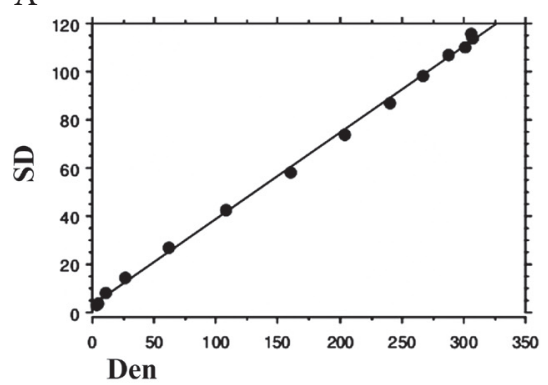

Outward current density

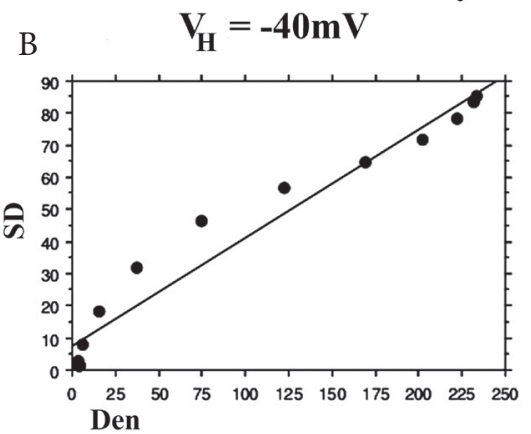

Outward current density
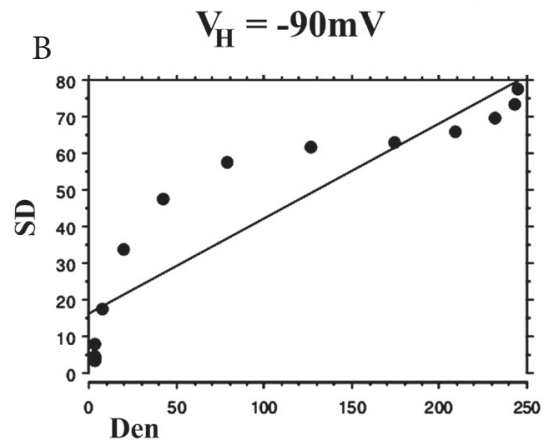

$\mathrm{C}$

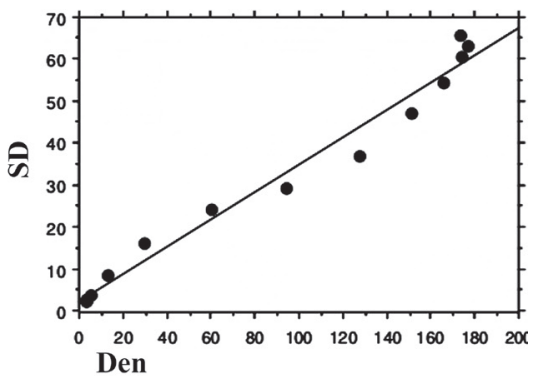

C

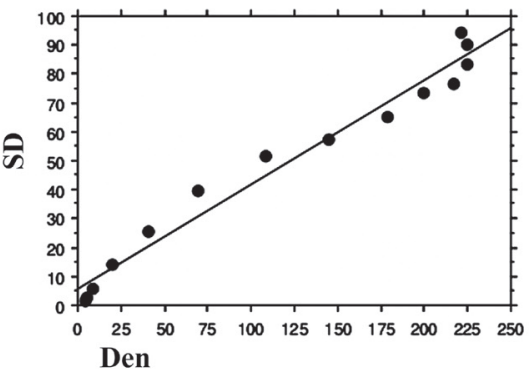

Figure 6. Linear model data fitting for the comparison of SD $v$ s Den for outward currents at $V_{H}=-40 m V$ and the $V_{H}=-90 m V$ for the solutions $\mathrm{A}, \mathrm{B}$ and $\mathrm{C}$.

and the Fisher's tests results for the comparison of each pair of solutions used.

By comparing expected and observed results, for example, using $+40 \mathrm{mV}$ as stimulus level and considering $E_{\text {ions }}$ both for the inward and outward current as shown in Table 1, the expected $D e n_{\text {inw }}$ computed by Eq. 3, for the holding level of $-40 \mathrm{mV}$ are respectively $-49.38 g_{\mathrm{Na}}$ for solution $\mathrm{A}$ and -25.85 $g_{\mathrm{Na}}$ for solution B. The expected difference $(\mathrm{A}-\mathrm{B})$ is, then $-49.38 g_{\mathrm{Na}}-(-25.85) g_{\mathrm{Na}}=-22.23 g_{\mathrm{Na}}$ while the observed value is 62.62 (Table 2).

The same computation, for Den $n_{\text {outw }}$ by using Eq. 4 , gives an expected difference of 0.15 while the observed one is 25.64. Similar results are obtained for both holding level of -40 and of $-90 \mathrm{mV}$.

It appears, from the above results, that observed responses do not depend on the driving force $\left(V_{m}-E_{i o n}\right)$ and consequently, can only be dependent on different values of membrane conductance $\left(g_{m}\right)$ among the cells.

In our results we also noted that Den outw $_{\text {is always larger }}$ than $D e n_{\text {inw. }}$ We have also compared the maximal mean $D e n_{\text {inw }}$ with the maximal mean $D e n_{\text {outw }}$ and the ratios are $0.12,0.36$ and 0.28 for solutions A, B and C, respectively, for holding level $-40 \mathrm{mV}$. For the holding level of $-90 \mathrm{mV}$, the ratios are $0.44,0.48$ and 0.42 , respectively. Obviously, this ratio is inverted for solution D. From these results we can conclude that inward currents are always less than $50 \%$ of the outward currents. This could be explained by the larger driving force acting on $\mathrm{K}^{+}$ions with respect to $\mathrm{Na}^{+}$ions as well as due to a larger conductance of $\mathrm{K}^{+}$than $\mathrm{Na}^{+}$for depolarizing steps.

\section{Discussion}

The present work represents a study of the variabilities of the basic electrophysiological properties of the cell line SH-SY5Y.

Our experiments, in whole cell configuration, showed a large variability of response to depolarizing stimuli in voltage clamp configuration. To normalize the responses to the size of the cell we used the current density (Den) in our statistical analysis. To analyse the variability around the mean responses to each depolarizing step, we used the standard deviation (SD).

A large SD was observed both for inward and outward peak currents at the two holding levels tested $(-40 \mathrm{mV}$ and $-90 \mathrm{mV}$ ). In all cases, the SD showed a linear dependence on the amplitude of the mean current density. 
Table 2. ANOVA and Fisher's test for comparison of inward current densities $\left(\operatorname{Den}_{\text {inw }}\right)$ at $\mathrm{V}_{\mathrm{H}}=-40 \mathrm{mV}$

\begin{tabular}{|c|c|c|c|c|c|}
\hline \multirow{2}{*}{$\begin{array}{c}\text { Stimulus } \\
\text { level } \\
(\mathrm{mV})\end{array}$} & \multirow{2}{*}{$\begin{array}{c}\mathrm{F}_{0.05} \\
\text { (ANOVA) }\end{array}$} & \multicolumn{4}{|c|}{$\operatorname{Den}_{i n w}$ (Fisher's test) } \\
\hline & & A-B & A-C & A-D & B-C \\
\hline-40 & $3.52^{*}$ & -0.29 & -1.60 & -1.68 & $-1.29^{\star}$ \\
\hline-30 & $7.52^{\star \star}$ & 0.98 & -1.03 & -0.75 & $-2.00^{\star}$ \\
\hline-20 & $3.58^{*}$ & -1.11 & $-3.07^{\star}$ & $-3.16^{*}$ & -1.96 \\
\hline-10 & $3.36^{\star}$ & -3.96 & $-9.30^{*}$ & $-9.30^{\star}$ & -5.34 \\
\hline 0 & $4.45^{\star}$ & 10.74 & -1.11 & -8.84 & -11.85 \\
\hline 10 & $13.93^{\star *}$ & $40.11^{\star *}$ & 19.10 & -8.26 & -21.01 \\
\hline 20 & $21.63^{\star *}$ & $62.77^{\star \star}$ & 31.31 & -6.90 & $-31.46^{*}$ \\
\hline 30 & $24.03^{\star *}$ & $67.81^{\star *}$ & 32.76 & -5.01 & $-35.05^{\star}$ \\
\hline 40 & $23.21^{\star \star}$ & $62.62^{\star *}$ & 29.70 & -3.95 & $-32.91^{\star}$ \\
\hline 50 & $22.20^{\star \star}$ & $52.92^{\star *}$ & 23.92 & -2.47 & $-29.01^{\star}$ \\
\hline 60 & $17.44^{\star *}$ & $38.75^{\star *}$ & 15.97 & -1.67 & $-22.78^{\star}$ \\
\hline 70 & $12.91^{\star \star}$ & $25.39^{\star *}$ & 11.02 & -1.68 & $-14.37^{\star}$ \\
\hline 80 & $7.76^{* *}$ & $14.151^{\star}$ & 6.81 & -1.66 & -7.33 \\
\hline 90 & 0.33 & 0.40 & 1.99 & -2.76 & 1.59 \\
\hline
\end{tabular}

The difference among the means of the solution $\mathrm{A}, \mathrm{B}$ and $\mathrm{C}$ have been tested for the hypothesis $\mathrm{HO}=0$ (i.e., that there are not differences among means). The comparison of the solutions A and $D$ was included to show the possible influence of outward currents on inward peak currents. Significant differences for ${ }^{\star} p \leq 0.05$ and ${ }^{* *} p \leq 0.001$

Table 4. ANOVA and Fisher's test for comparison of outward current densities $\left(\right.$ Den $_{\text {outw }}$ ) at the $\mathrm{V}_{\mathrm{H}}=-40 \mathrm{mV}$

\begin{tabular}{|c|c|c|c|c|}
\hline \multirow{2}{*}{$\begin{array}{c}\text { Stimulus } \\
\text { level } \\
(\mathrm{mV})\end{array}$} & \multirow{2}{*}{$\begin{array}{c}\mathrm{F}_{0.05} \\
\text { (ANOVA) }\end{array}$} & \multicolumn{3}{|c|}{$\operatorname{Den}_{\text {outw }}$ (Fisher's test) } \\
\hline & & $A-B$ & $\mathrm{~A}-\mathrm{C}$ & B-C \\
\hline-40 & $3.70^{*}$ & 0.45 & 1.30 & 0.85 \\
\hline-30 & $7.91^{* *}$ & 0.07 & 0.63 & 0.56 \\
\hline-20 & $18.93^{\star *}$ & $2.69^{\star *}$ & $2.72^{\star *}$ & 0.03 \\
\hline-10 & $56.48^{\star *}$ & $10.31^{\star \star}$ & $8.27^{\star *}$ & $-2.04^{*}$ \\
\hline 0 & $56.97^{* *}$ & $27.97^{\star *}$ & $20.70^{\star \star}$ & $-7.27^{\star}$ \\
\hline 10 & $44.18^{\star *}$ & $52.47^{\star *}$ & $37.78^{\star \star}$ & $-14.69^{*}$ \\
\hline 20 & $28.70^{* *}$ & $65.06^{\star \star}$ & $42.43^{*}$ & $-22.63^{*}$ \\
\hline 30 & $21.86^{\star *}$ & $54.56^{\star *}$ & $34.70^{*}$ & -19.86 \\
\hline 40 & $25.85^{\star *}$ & 25.64 & 20.05 & -5.59 \\
\hline 50 & $34.65^{\star *}$ & -6.61 & 10.60 & 17.22 \\
\hline 60 & $40.80^{\star *}$ & -30.93 & 4.8 & 35.73 \\
\hline 70 & $42.22^{\star *}$ & $-45.63^{\star}$ & 1.87 & $47.49^{*}$ \\
\hline 80 & $40.93^{\star *}$ & $-53.72^{\star}$ & 1.00 & $54.72^{*}$ \\
\hline 90 & $39.47^{\star *}$ & $-59.01^{\star}$ & 1.37 & $60.38^{*}$ \\
\hline
\end{tabular}

The difference among the means of the solutions $\mathrm{A}, \mathrm{B}$ and $\mathrm{C}$ have been tested for the hypothesis $\mathrm{H} 0=0$ (i.e., that there are not differences among means). Significant differences for ${ }^{\star} p \leq 0.05$ and ${ }^{* *} p \leq 0.001$.
Table 3. ANOVA and Fisher's test for comparison of inward current densities $\left(\right.$ Den $\left._{\text {inw }}\right)$ at the $\mathrm{V}_{\mathrm{H}}=-90 \mathrm{mV}$

\begin{tabular}{cccccc}
\hline Stimulus & \multirow{2}{*}{$\begin{array}{c}\mathrm{F}_{0.05} \\
\text { level }\end{array}$} & \multicolumn{4}{c}{ Den $_{\text {inw }}$ (Fisher's test) } \\
\cline { 5 - 6 }$(\mathrm{mV})$ & $(\mathrm{ANOVA})$ & $\mathrm{A}-\mathrm{B}$ & $\mathrm{A}-\mathrm{C}$ & $\mathrm{A}-\mathrm{D}$ & $\mathrm{B}-\mathrm{C}$ \\
\hline-40 & 1.17 & 0.50 & -1.56 & 1.64 & -2.06 \\
-30 & $24.40^{* *}$ & $-14.37^{* *}$ & $-13.20^{*}$ & 6.51 & 1.17 \\
-20 & $53.91^{* *}$ & $-58.57^{* *}$ & $-37.52^{* *}$ & 7.50 & $21.05^{*}$ \\
-10 & $56.46^{* *}$ & $-86.71^{* *}$ & -56.29 & 1.89 & $30.41^{*}$ \\
0 & $21.23^{* *}$ & $-63.88^{* *}$ & $-46.05^{*}$ & 4.52 & -17.83 \\
10 & 1.91 & -17.86 & -21.43 & 5.92 & -3.57 \\
20 & 1.59 & 18.15 & -5.37 & 5.78 & -23.53 \\
30 & $5.16^{*}$ & $36.19^{*}$ & 2.98 & 4.91 & $-33.21^{*}$ \\
40 & $7.19^{* *}$ & $40.80^{*}$ & 4.52 & 4.37 & $-36.29^{*}$ \\
50 & $7.65^{* *}$ & $30.04^{*}$ & 6.58 & 4.27 & $-32.47^{*}$ \\
60 & $8.21^{* *}$ & $34.29^{*}$ & 2.87 & 3.29 & $-31.42^{*}$ \\
70 & $6.18^{*}$ & $24.21^{*}$ & 0.56 & 1.55 & $-23.66^{*}$ \\
80 & 1.64 & 10.65 & 2.06 & -0.37 & -8.59 \\
90 & 0.12 & -3.33 & -1.31 & -4.01 & 2.02 \\
\hline
\end{tabular}

The difference among the means of the solution $\mathrm{A}, \mathrm{B}$ and $\mathrm{C}$ have been tested for the hypothesis $\mathrm{H} 0=0$ (i.e., that there are not differences among means). The comparison of solutions A and D was included to show the possible influence of outward currents on inward peak currents. Significant differences for ${ }^{*} p \leq 0.05$ and ${ }^{*} p \leq 0.001$.

Table 5. ANOVA and Fisher's test for comparison of outward current densities $\left(\right.$ Den $\left._{\text {outw }}\right)$ at the $\mathrm{V}_{\mathrm{H}}=-90 \mathrm{mV}$

\begin{tabular}{|c|c|c|c|c|}
\hline \multirow{2}{*}{$\begin{array}{c}\text { Stimulus } \\
\text { level } \\
(\mathrm{mV})\end{array}$} & \multirow{2}{*}{$\begin{array}{c}\mathrm{F}_{0.05} \\
\text { (ANOVA) }\end{array}$} & \multicolumn{3}{|c|}{ Den $_{\text {outw }}$ (Fisher's test) } \\
\hline & & $A-B$ & $\mathrm{~A}-\mathrm{C}$ & $\mathrm{B}-\mathrm{C}$ \\
\hline-40 & $2.72^{*}$ & -0.38 & -1.41 & -1.03 \\
\hline-30 & $3.66^{*}$ & 1.67 & -0.20 & -1.88 \\
\hline-20 & $15.95^{\star *}$ & $7.78^{\star *}$ & 1.96 & $-5.82^{*}$ \\
\hline-10 & $38.98^{\star *}$ & $23.32^{* *}$ & $7.19^{\star}$ & $-16.13^{* *}$ \\
\hline 0 & $47.04^{\star *}$ & $54.51^{\star *}$ & $21.49^{\star}$ & $-33.02^{\star *}$ \\
\hline 10 & 1.91 & -17.86 & -21.43 & -3.57 \\
\hline 20 & $36.49^{* *}$ & $117.10^{\star *}$ & $51.94^{*}$ & $-65.16^{* *}$ \\
\hline 30 & $34.45^{\star *}$ & $125.75^{\star *}$ & $59.33^{*}$ & $-66.42^{\star}$ \\
\hline 40 & $35.00^{* *}$ & $113.75^{\star \star}$ & $61.51^{*}$ & $-52.24^{\star}$ \\
\hline 50 & $39.31^{\star *}$ & $93.30^{\star *}$ & $68.06^{*}$ & -25.24 \\
\hline 60 & $42.84^{* *}$ & $79.24^{* *}$ & $71.42^{*}$ & -7.82 \\
\hline 70 & $42.60^{\star *}$ & $70.03^{*}$ & $76.58^{*}$ & 6.55 \\
\hline 80 & $39.43^{\star *}$ & $64.19^{*}$ & $82.75^{\star}$ & 18.56 \\
\hline 90 & $34.16^{\star *}$ & $61.41^{*}$ & $84.65^{*}$ & 23.24 \\
\hline
\end{tabular}

The difference among the means of the solution $\mathrm{A}, \mathrm{B}$ and $\mathrm{C}$ have been tested for the hypothesis $\mathrm{H} 0=0$ (i.e., that there are not differences among means). Significant differences for ${ }^{\star} p \leq 0.05$ and ${ }^{* *} p \leq 0.001$. 
Surprisingly, results obtained with the three groups (A, $\mathrm{B}$ and $\mathrm{C}$ ) were statistically different for the amplitude of the response (Den) for the steps that gave significant responses. This difference in the response amplitude cannot be explained by the different ionic concentration as we have demonstrated by simple computations.

The variability expressed as SD of Den showed a clear linear dependence on the amplitude of the response for each solution and for both the holding levels used $(-40 \mathrm{mV}$ and $-90 \mathrm{mV}$ ). Also variability among groups still follow the same dependence, in the sense that "the larger the current density, the bigger the variability". In addition, resting potential in the three groups was also statistically different.

Both response variability inside each group and among groups suggested that this effect was due to the variability of peak membrane conductance $\left(g_{m}\right)$ for $\mathrm{Na}^{+}$and $\mathrm{K}^{+}$among cells.

Current-clamp experiments showed the inability of these cells to produce spikes when the holding current was set to $0 \mathrm{pA}$ (virtually at resting potential). They produced a single spike only when membrane potential was driven toward more negative values and closer to resting potentials of a typical real neuron $(\leq-50 \mathrm{mV})$. In other words, from this point of view, they behave as "neuron-like" when their membrane potential is "neuron-like".

The large variability of conductance is directly related to the type of voltage gated channels in the membrane, to their density and to their functionality. Park et al. (2010) have shown, by RT-PCR experiments, that different levels of $\mathrm{Na}_{\mathrm{V} 1.7}\left(\mathrm{Na}^{+}\right.$ channel) and $\mathrm{BK}_{\mathrm{Ca}}$ (Big potassium calcium-dependent channel) were present in undifferentiated SH-SY5Y cells depending on the expression (or not) of the tumour marker CD133.

However, we observed, during the same recording session, a large difference in the responses among cells very close to each other on the same culture slide, and then likely belonging to the same population. Consequently, we can conclude that the large variability observed can be due to the heterogeneity of sub-populations of these cells and/or to a possible deficit in the regulation of expression of genes involved in the density of different types of channels in the plasma membrane.

It is not an easy task to explain the statistical differences observed among the different groups. Testing the influence of other parameters, such as the time and the passage of the cell culture, will require the use of additional experimental designs. Also comparison of variability of responses between undifferentiated and differentiated cells by using for example retinoic acid, will be a useful system to fully understand the origin of the variability of electrophysiological responses of this cell-line.

From the results presented herein, we can conclude that these cells, although could be a useful model in some neurobiological experiments, should be considered with great caution for the evaluation of electrophysiological data.

\section{References}

Agholme L., Lindström T., Kågedal K., Marcusson J., Hallbeck M. (2010): An in vitro model for neuroscience: differentiation of SH-SY5Y cells into cells with morphological and biochemical characteristics of mature neurons. J. Alzheimers Dis. 20, 1069-1082

Dunckley T., Lukas R. J. (2006): Nicotinic modulation of gene expression in SH-SY5Y neuroblastoma cells. Brain Research 1116, 39-49 http://dx.doi.org/10.1016/j.brainres.2006.07.111

Encinas M., Iglesias M., Liu Y., Wang H., Muhaisen A., Cena V., Gallego C., Comella J. X. (2000): Sequential treatment of SH-SY5Y cells with retinoic acid and brain-derived neurotrophic factor gives rise to fully differentiated, neurotrophic factor-dependent, human neuron-like cells. J. Neurochem. 75, 991-1003 http://dx.doi.org/10.1046/j.1471-4159.2000.0750991.x

Forsythe I. D., Lambert D. G., Nahorski S. R., Lindsdell P. (1992a): Elevation of cytosolic calcium by cholinoreceptor agonists in SH-SY5Y human neurobalstoma cells: estimation of the contribution of voltage-dependent currents. Br. J. Pharmacol. 107, 207-214 http://dx.doi.org/10.1111/j.1476-5381.1992.tb14488.x

Forsythe I. D., Lindsdell P., Stanfield P. R. (1992b): Unitary Acurrent of rat locus coeruleus neurones grown in cell culture: rettification caused by internal $\mathrm{Mg}++$ and $\mathrm{Na}+$. J. Physiol. 213, 21-30

Friederich P., Dilger J. P., Pongs O., Urban B. W. (2002): Kv3.1 expression in human neuroblastoma SH-SY5Y cells. Pflügers Arch. 439, R427

Jämsä A., Hasslund K., Cowburn R. F., Bäckström A., Vasänge M.(2004): The retinoic acid and brain-derived neurotrophic factor differentiated SH-SY5Y cell line as a model for Alzheimer's disease-like tau phosphorylation. Biochem. Biophys. Res. Commun. 319, 993-1000 http://dx.doi.org/10.1016/j.bbrc.2004.05.075

Park J. H., Park S. J., Chung M. K., Jung K. H., Choi M. R., K. Yangmi, Chai Y. G., Kim S. J., Park K. S. (2010): High expression of large-conductance $\mathrm{Ca} 2+$-activated $\mathrm{K}+$ channel in the CD133+ subpopulation of SH-SY5Y neuroblastoma cells. Biochem. Biophys. Res. Commun. 396, 637-642 http://dx.doi.org/10.1016/j.bbrc.2010.04.142

Toselli M., Tosetti T., Taglietti V. (1996): Functional changes in sodium conductances in human neuroblastoma cell line SH-SY5Y during in vitro differentiation. J. Neurophysiol. 76, 3920-3927

Tosetti T., Taglietti V., Toselli M. (1998): Functional changes in potassium conductances of the human neuroblastoma cell line SH-SY5Y during in vitro differentiation. J. Neurophysiol. $79,648-658$

Xie H. R., Hu L. S., Li G. Y. (2010): SH-SY5Y human neuroblastoma cell line: in vitro cell model of dopaminergic neurons in Parkinson's disease. Chin. Med. J. (Engl) 123, 1086-1092

Received: April 23, 2013

Final version accepted: August 26, 2013 